\title{
Celsr1, a Neural-Specific Gene Encoding an Unusual Seven-Pass Transmembrane Receptor, Maps to Mouse Chromosome 15 and Human Chromosome 22qter
}

\author{
Anna-Katerina Hadjantonakis,*,1 W. John Sheward,† Anthony J. Harmar,† Louis de Galan,‡ \\ Jan M. N. Hoovers, $\ddagger$ and Peter F. R. Little*,2 \\ *Wolfson Laboratories, Department of Biochemistry, Imperial College of Science, Technology and M edicine, South Kensington, \\ London SW 7 2AZ, United Kingdom; †M RC Brain M etabolism Unit, Royal Edinburgh Hospital, Morningside Park, \\ Edinburgh, United Kingdom; and ¥Institute of Human Genetics, University of Amsterdam, \\ Academic Medical Centre, Amsterdam, The Netherlands
}

Received June 24, 1996; accepted June 30, 1997

\begin{abstract}
We have identified Celsr 1, a gene that encodes a developmentally regulated vertebrate seven-pass transmembrane protein. The extracellular domain of Celsr 1 contains two regions each with homology to distinct classes of well-characterized motifs found in the extracellular domains of many cell surface molecules. The most $\mathbf{N}$-terminal region contains a block of contiguous cadherin repeats, and C-terminal to this is a region containing seven epidermal growth factor-like repeats interrupted by two laminin A G-type repeats. Celsr 1 is unique in that it contains this combination of repeats coupled to a seven-pass transmembrane domain. As part of the characterization of the Celsrl gene, we have determined its chromosomal map location in both mouse and human. The E uropean Collaborative Interspecific Backcross (EUCIB) and BXD recombinant inbred strains were used for mapping Celsrl cDNA clones in the mouse, and fluorescence in situ hybridization was used to map human Celsr 1 cosmid clones on metaphase chromosomes. We report that Celsr1 maps to proximal mouse Chromosome 15 and human chromosome 22qter, a region of conserved synteny. Reverse transcriptase-polymerase chain reaction analysis and in situ hybridization were used to determine the spatial restriction of Celsr 1 transcripts in adult and embryonic mice. The results presented here extend our previous finding of expression of the Celsr 1 receptor in the embryo and show that expression continues into adult life when expression in the brain is localized principally in the ependymal cell layer, choroid plexus, and the area postrema. 1997 Academic Press
\end{abstract}

\section{INTRODUCTION}

The Celsr1 gene (Cadherin EGF LAG seven-pass Gtype Receptor, also referred to as ME2) encodes an or-

\footnotetext{
${ }^{1}$ Present address: Samuel Lunenfeld Research Institute, Mount Sinai Hospital, Toronto M5G 1X5, Canada.

${ }^{2}$ To whom correspondence should be addressed. Tel ephone: 44-171 594 5288. Fax: 44-171 823 7525. E-mail: p.little@ic.ac.uk.
}

phan seven-pass transmembrane G-protein coupled receptor (GCR) with homology to the peptide hormone binding group of receptors, family B (Kolakowski, 1994; available on the public database http://receptor.mgh. harvard.edu).

The extracellular domain of Celsr 1 contains two regions each with homology to distinct classes of wellcharacterized motifs found in the extracellular domains of many cell surface molecules. The most $\mathrm{N}$-terminal region contains a block of contiguous cadherin repeats (Geiger and Ayalon, 1992), and C-terminal to this is a region containing seven epidermal growth factor (EGF)-like repeats (Davis, 1990) interrupted by two laminin A G-type (LAG) repeats (Patthy, 1992). Celsr 1 is unique in that it contains this combination of repeats coupled to a seven-pass transmembrane domain. Outside of the repeat motifs, Celsr 1 is most highly related to EMR1 (Baud et al., 1995) and CD97 (Hamann et al., 1995), which are unusual members of family $B$ of sevenpass transmembrane G-protein coupled receptors (Kolakowski, 1994). Celsr 1, EMR1, and CD97 differ from other B family GCRs in that they have large N-terminal extracellular domains containing multiple EGFlike repeats, but Celsr 1 is unique in also possessing cadherin repeats in its extracellular domains. A full description of the structure of Celsrl and its expression during early embryogenesis will be presented elsewhere (A.-K.H. and P.F.R.L., manuscript in preparation).

A number of G-protein coupled receptors are altered in several human genetic disorders and mouse mutants (Coughlin, 1994). Examples of these include the Melanocyte Stimulating Hormone receptor mutated in various coat color mutants including yellow (e), sombre (Eso), and tobacco darkening (Etob) (Robbins et al., 1993), the growth hormone rel easing hormone receptor mutated in little mice (Lin et al., 1993; Godfrey et al., 1993), and the endothelin B receptor mutated in the piebald-lethal mouse mutant and Hirchsprung's dis- 
ease in humans (Hosoda et al., 1994; Puffenberger et al., 1994). The expression of Celsr 1 is spatiotemporally restricted during mouse embryonic development (A.-K.H. and P.F.R.L., manuscript in preparation) and we wished to analyse gene expression in the adult to address the possible relationship of Celsr 1 to existing mutations by establishing the chromosomal location of the Celsrl gene in mouse and humans.

\section{MATERIALS AND METHODS}

DNA preparation and analysis. DNA preparations were carried out by standard methods detailed in Little (1987) and Sambrook et al. (1989). Radioactive signals were visualized either by standard autoradiography or by the use of a PhosphorI mager and I mageQuant software (Molecular Dynamics).

I solation of mousecDNA clones. The ME2(19) and ME2(2) clones were isolated from a mouse 8.5 days post coitum (d.p.c.) embryonic CDNA library constructed in $\lambda$ gt10 (Farnher et al., 1987). ME2(2) and ME2(19) together comprise a 2407-bp cDNA whose sequence has been deposited in GenBank (Accession No. AF 006014). The cDNA includes sequences from the middle of transmembrane region two
(TMII) to the N-terminus (approximately 510 amino acids) and an additional $878 \mathrm{bp}$ from the $3^{\prime}$ untranslated region, which is $1811 \mathrm{bp}$ in total length. The full Celsr 1 cDNA sequence of $>11 \mathrm{~kb}$ will be published elsewhere.

Isolation of human cosmid clones. The human Celsrl cosmid clones were isolated by screening a human cosmid library constructed in pCos2EMBL (Ehrich et al., 1987) at reduced stringency using the ME2(19) mouse CDNA clone.

RT-PCR detection of transcripts. Total RNA was prepared from various adult mouse tissues using the acid guanidinium-phenolchloroform procedure (Chomczynski and Sacchi, 1987). One microgram was used for reverse transcription using an oligo(dT) primer in a total volume of $30 \mu \mathrm{l}$. Five microliters of the first-strand CDNA was subjected to PCR under standard buffer conditions with Taq polymerase (Promega). The Celsr 1 gene-specific primers used were PLKH23 (5'-TTTGTCCTTCTCTCGCTCGTTC-3') and PLKH24 (5'CAAAGCTCCAAATCAGGGTATCC-3'). The HPRT primers were taken from Koopman (1993): HPRTla (5'-CCTGCTGGATTACATTTACATTAAAGCACTG-3') and HPRT1b (5'-GTCAAGGGCATATCCAACAACAAAC-3'). PCR amplifications were subjected to a "hot start" followed by 35 cycles of $93^{\circ} \mathrm{C}, 30 \mathrm{~s} ; 60^{\circ} \mathrm{C}, 1 \mathrm{~min} ; 72^{\circ} \mathrm{C}, 1 \mathrm{~min}$; with one final extension step at $72^{\circ} \mathrm{C}$ for $10 \mathrm{~min}$. The Celsr $1 \mathrm{PLKH} 23$ / PLKH24 primer pair is directed against transmembrane domains I to IV and does not yield any products with genomic DNA. Sequencing
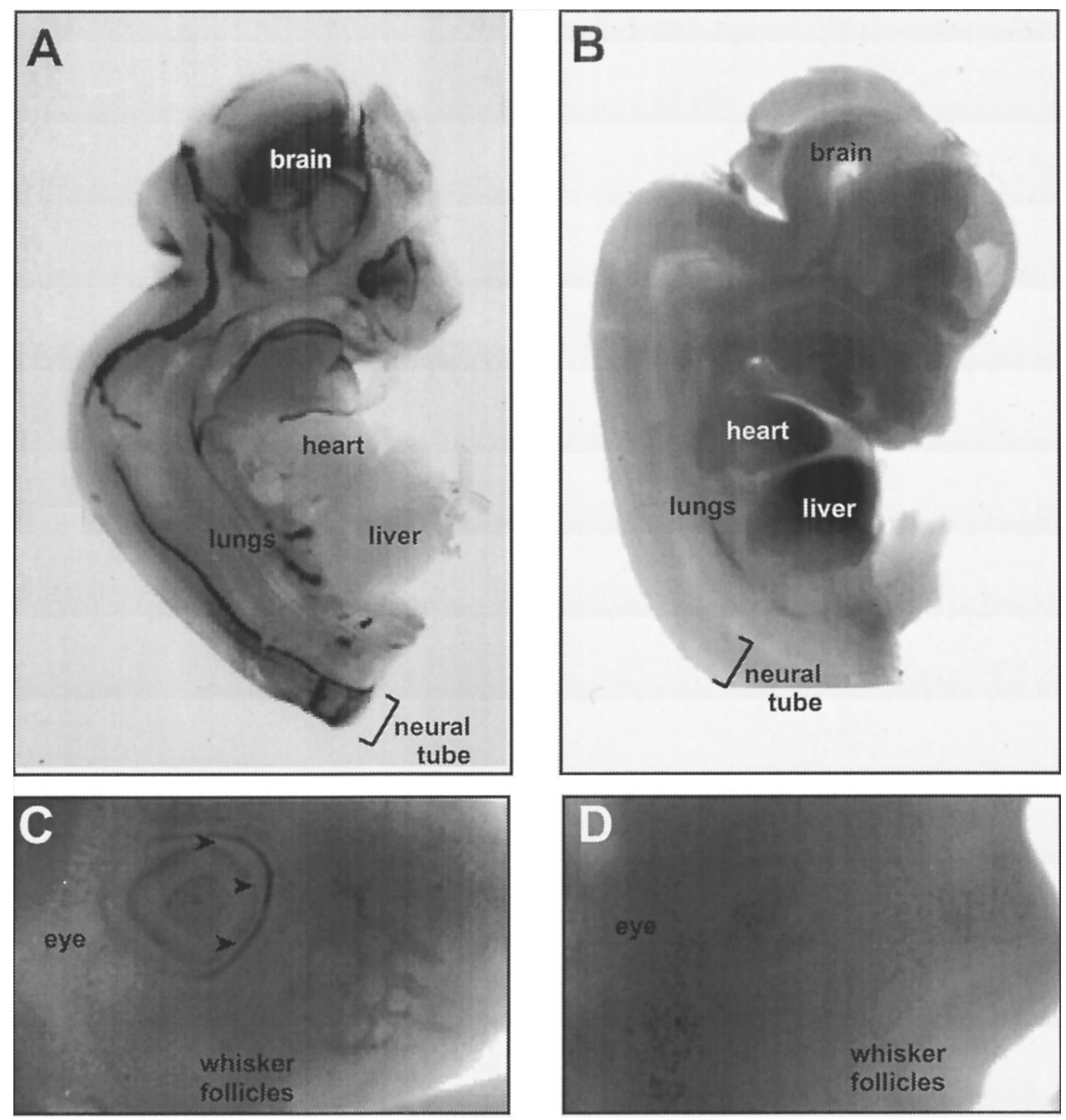

FIG. 1. In situ hybridization to Celsrl transcripts in the midgestation mouse embryo. Whole-mount in situ hybridization of an antisense Celsr 1 cRNA probe to (A) a transversely cut 12.5-d.p.c. embryo showing localized gene expression in the CNS and (C) the face of a 12.5-d.p.c. mouse embryo showing expression in the nascent eyelid (arrowheads) and prospective whisker follicles. Sense strand controls (B and D). 
and hybridization to authentic Celsr 1 cDNA clones showed that the amplified product was specific for the Celsrl locus (data not shown).

Recombinant inbred (RI) strain mapping. DBA/2J and C57BL/6 inbred strains of mice were purchased from Olak through the I mperial College Central Biomedical Services (CBS) and maintained at the CBS unit (Biochemistry Department, Imperial College). DNA from the 26 BXD recombinant inbred strains was purchased from The J ackson Laboratory DNA Resource (Bar Harbor, ME). Linkage was determined by comparing the strain distribution pattern (SDP) for alleles at the locus of interest with those already typed in the series. Analysis of the SDPs was carried out using the RI manager computer program (Manly and Elliot, 1991) and by Dr. Ben Taylor (The J ackson Laboratory), who compared our SDP to all others in his BXD database (Taylor, 1989).

EUCIB mapping. A facility for genetic mapping of the mouse genome (Breen et al., 1994) available from the UK Human Genome Mapping Project Resource Centre (Hinxton, Cambridge) was used. A Taql RFLV was obtained at the Celsr 1 locus between Mus spretus and C57BL/6 using the ME2(2) clone as a probe.

Prometaphase chromosomes. High-resolution chromosomes from peripheral lymphocytes were obtained according to a double synchronization technique (Ronne, 1985).

Fluorescence in situ hybridization (FISH). Probes were biotinylated by nick-translation, according to the manufacturer's specifications (Life Technologies nick-translation kit). Chromosomal in situ hybridization, posthybridization washes, Q-banding using DAPI/actinomycin D, and probe localization were performed as described previously (Hoovers et al., 1992).

Wholemount in situ hybridizations. Mice were killed by cervical dislocation and the uteri removed by standard procedures (Hogan et al., 1986). Processing and whole-mount in situ hybridizations were performed essentially as described previously (Conlon and Rossant, 1992; Wilkinson, 1992).

Radioactive in situ hybridization to adult brain sections. In situ hybridization on sections of adult mouse brain was carried out using a modification of a method described previously (Sheward et al., 1995). In brief, adult mice (F 1 hybrid of strains $\mathrm{C} 3 \mathrm{H} / \mathrm{HeH}$ and 101/ $\mathrm{H}$ bred in the Animal House, Department of Pharmacology, University of Edinburgh) were killed by an overdose of sodium pentobarbitone and the brains removed and frozen $\left(-35^{\circ} \mathrm{C}\right)$ rapidly in isopentane. Serial coronal sections $(10 \mu \mathrm{m})$ were cut on a cryostat, fixed with $4 \%$ paraformaldehyde in $0.1 \mathrm{M}$ phosphate buffer for $5 \mathrm{~min}$, acetylated, dehydrated, and delipidized, before hybridization at $50^{\circ} \mathrm{C}$ for 18-20 h with sense or antisense strand Celsr 1 riboprobes labeled with ${ }^{32} \mathrm{P}$. F or riboprobe synthesis the plasmid containing ME2(19) was digested with Xhol and transcribed with T3 RNA polymerase; for a control the plasmid was linearized with BamHI and transcribed with T7 RNA polymerase to generate the sense-strand probe. After hybridization, sections were washed in $4 \times$ SSC at room temperature, followed by $2 \times \mathrm{SSC}$ at $37^{\circ} \mathrm{C}$ and digestion with RNaseA. After further washes in $1 \times \mathrm{SSC}$ at $50^{\circ} \mathrm{C}$ and $0.1 \times \mathrm{SSC}$ at $60^{\circ} \mathrm{C}$, sections were dehydrated in increasing concentrations of ethanol, dried under vacuum, and dipped in photographic emulsion (IIford K 5 Nuclear emulsion, diluted 1:1 with distilled water). Exposure was for 10 weeks after which slides were developed, fixed, and counterstained with $1 \%$ aqueous pyronin.

\section{RESULTS}

\section{Expression of Celsr 1 in Embryonic and Adult Mouse Tissues}

Celsrl is a large ( $>11 \mathrm{~kb})$ and low-abundance transcript, and as a consequence we have been unable to detect a signal on Northern blots containing up to 10 $\mu \mathrm{g}$ poly(A) RNA isolated from either dissected embryonic or adult tissues. Baud et al. (1995) reported similar difficulties in detection of EMR1 transcripts. We have
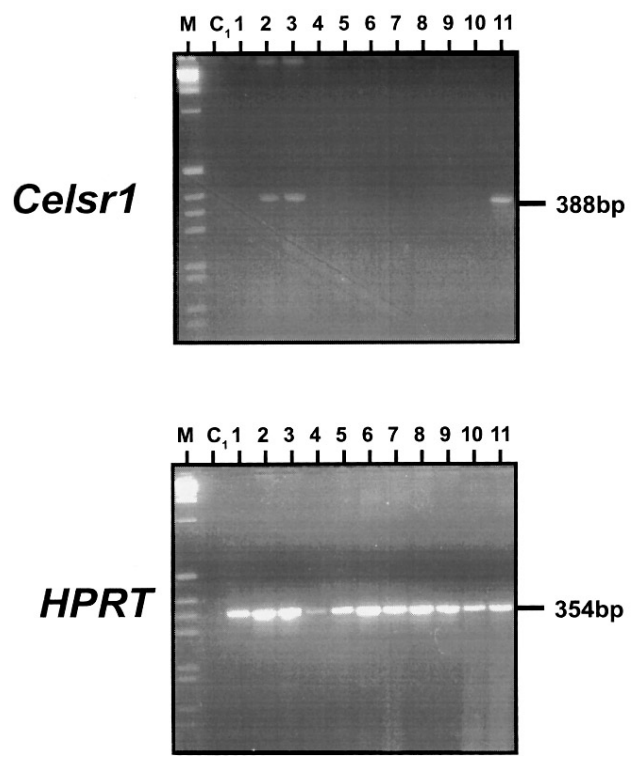

FIG. 2. RT-PCR analysis of Celsr 1 expression in adult mouse tissues. Lung (lane 1), brain (lane 2), spinal cord (lane 3), kidney (lane 4), liver (lane 5), spleen (lane 6), heart (lane 7), muscle (lane 8), thymus (lane 9), intestine (lane 10), eye (lane 11). $\mathbf{C}_{\mathbf{1}}$, no Taq polymerase control. $\mathbf{M}$, the marker is a Life Technologies kilobase ladder.

instead used a combination of whole-mount nonradioactive in situ hybridization to embryos, radioactive in situ hybridization to sections of adult tissues, and RTPCR analysis to identify the sites of expression of Celsr 1 transcripts in embryonic and adult tissues.

Whole-mount in situ hybridization analysis of 11.5d.p.c. embryos detected significant levels of Cel sr 1 transcripts in the neural tube, brain, lung epithelium, and nascent eyelid (Fig. 1) as well as other ectodermally derived regions. A complete expression analysis of embryos prior to 11.5 d.p.c. will be published elsewhere (A.-K.H. and P.F.R.L., manuscript in preparation).

PCR was performed on first-strand CDNA prepared from various mouse adult tissues (Fig. 2) using the PLKH23/PLKH24 primer pair. Products from Celsr 1 transcripts were only detected in adult mouse brain, spinal cord, and eye RNAs, suggesting that the ectodermal-specific expression observed in embryos is maintained during adult life.

To refine the location of Celsrl transcripts in the adult brain, we used in situ hybridization to sections (Fig. 3). Expression of the Celsrl mRNA was seen chiefly in the ependymal cells lining the lateral, third, and fourth ventricles of the brain and the central canal of the spinal cord as well as in the choroid plexus and area postrema. Specificity of the hybridization was controlled by hybridization of similar sections with the sense strand riboprobe: no labeled cells were seen in any of these brain regions.

\section{Mapping of Celsr 1 in the Mouse Genome}

We have mapped Celsr 1 in the European interspecific backcross (EUCIB) (Breen et al., 1994) and the 
HADJ ANTONAKIS ET AL.
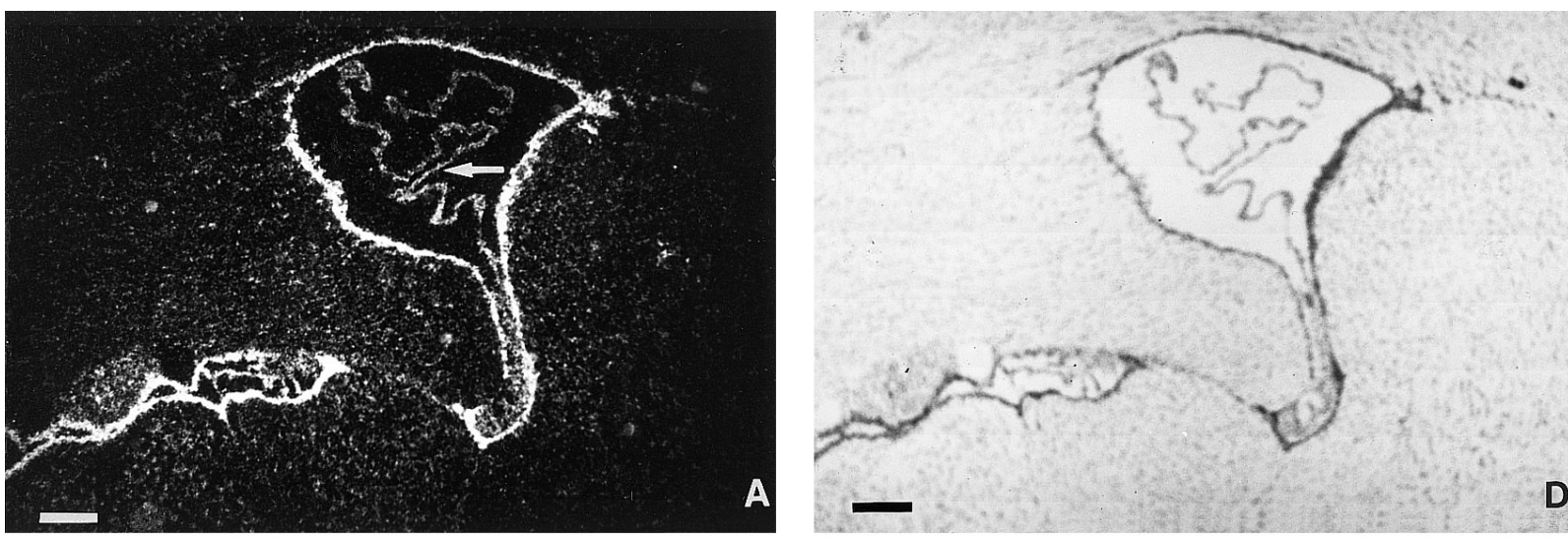

A
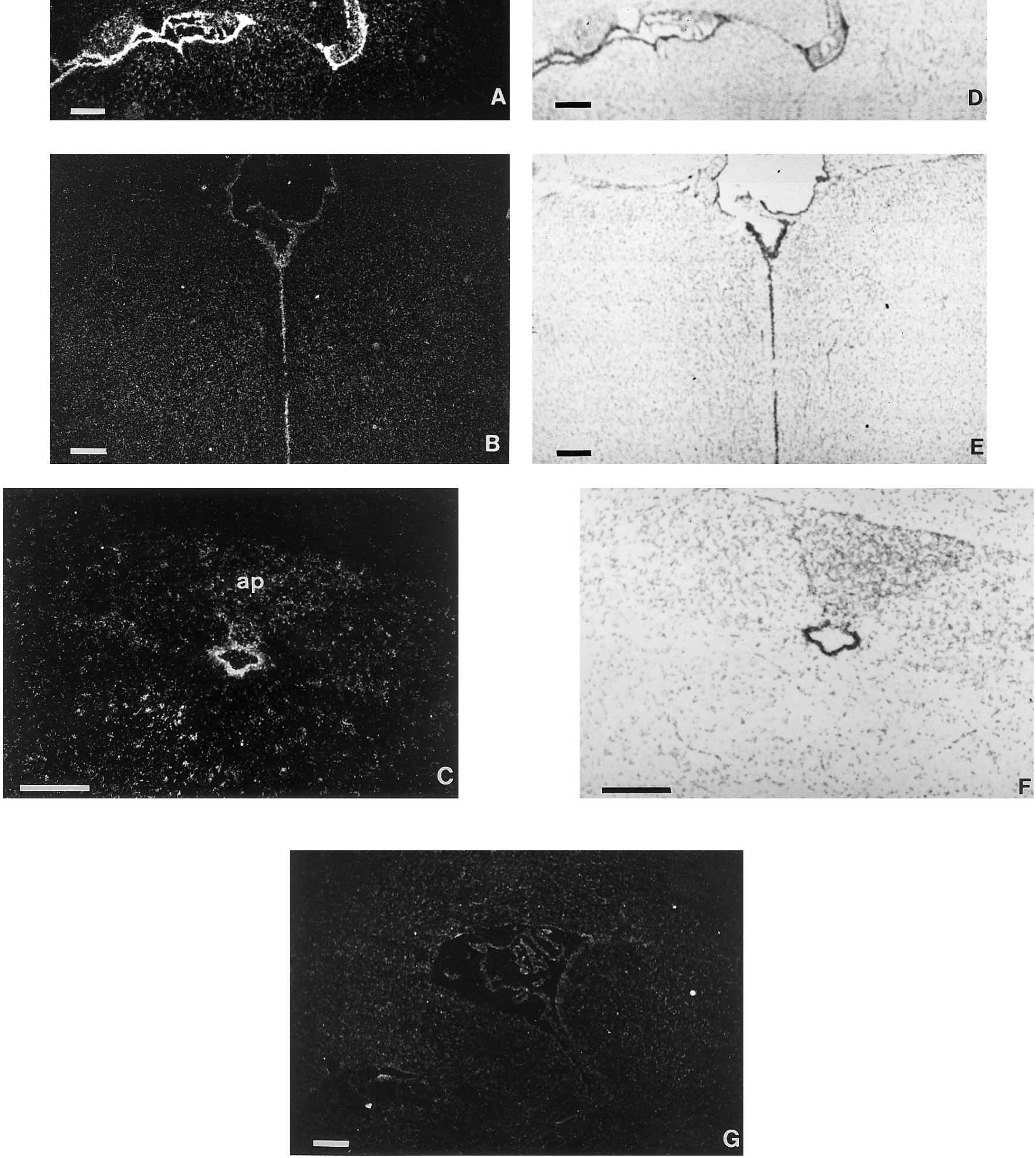


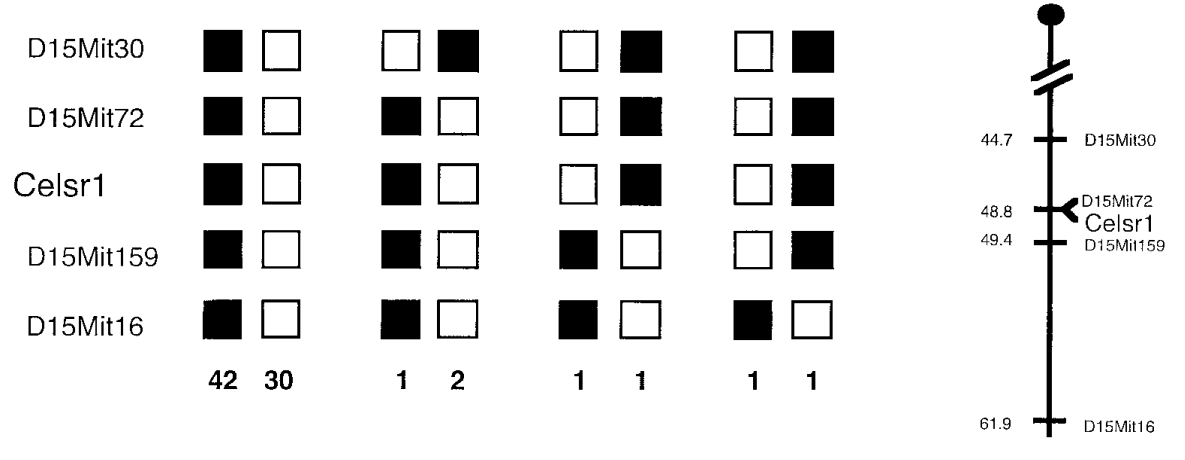

FIG. 4. Inheritance of Celsr 1 in the EUCIB. The segregation patterns of Celsr 1 and its closest flanking and anchor markers are shown on the left. Each column represents the genotype of backcross progeny. The black boxes represent the presence of a homozygote, the white boxes represent the presence of a heterozygote. The number of offspring inheriting each type of chromosome is listed at the bottom of each column. A partial chromosome linkage map showing the location of Celsr1 in relation to linked loci is shown on the right.

C57BL/6J $\times$ DBA/2J $(B X D)$ RI strain series (Taylor, 1989).

The EUCIB panel was screened by hybridization using the ME2(2) partial CDNA, which covers an area of the transcript containing part of the cytoplasmic tail and $3^{\prime}$ untranslated region (UTR). A Taql polymorphism was identified between the parental $M$. spretus and Mus musculus strain C57BL/6. Celsr 1 was typed for 94 mice: 40 (43\%) scored as homozygotes (C57BL/ 6 or M. spretus band only), and $54(57 \%)$ scored as heterozygotes (both C57BL/6 and M. spretus bands present). The data placed Cedsr 1 at $48.9 \mathrm{CM}$ on mouse chromosome 15 (Fig. 4). Celsr 1 does not recombine with D15Mit72 in the eight animals scored with this marker. Celsr1 is thus distal to the anchor locus D15Mit30, with the closest distal marker to Celsr 1 being D15Mit159 at position 49.5 .

To obtain a more comprehensive map location for the Celsrl gene in the mouse, we analyzed it in a second cross, the BXD RI strains. The BXD RI strains were analyzed by hybridization using two different partial CDNA clones, ME2(2) and ME2(19) as probes. Scal and Pstl (ME2(19)) and Stul (ME2(2)) polymorphisms were identified in the C57BL/6 and DBA/2J progenitor strains. SDPs were generated by scoring each strain for the inheritance of the B or D type allele: all three SDPs generated were identical. Comparison of the Celsr1 SDP with those of other loci typed in this BXD cross suggests linkage to Cyp2d (4/22 recombinants, $6.2 \pm 3.9 \mathrm{cM})$ and Pdgfb (5/25 recombinants, $7.1 \pm 4.1$ $\mathrm{CM}$ ) on mouse chromosome 15; Cyp2d and Pdgfb are inseparable in the BXD RI series since they have an identical SDP for the mice scored for both markers. Prior to the analysis of Celsrl in this cross, the marker order determined for this region of mouse chromosome 15 was centromere-D15Mit1-Pdgfb/ Cyp2d-Spt-2Hox-C(D15Mit16)-Pmv-42 (B.Taylor, pers. comm.).
Placing Celsr 1 on this map would have implied 10/25 recombination events with the flanking marker Spt-2. However, if we suggest that the gene order in the distal part of mouse chromosome 15 is in fact centromereD15Mit1- Pdgfb/ Cyp2d-Celsr1-Pmv-42- Hox-

C(D15M it16)-Spt-2, then we can place Celsr 1 distal to Pdgfb/ Cyp2d and proximal to Pmv-42 (7/26 recombinants, $11.29 \pm 6.1 \mathrm{CM})($ Table 1$)$. Thus the predicted map positions of Celsrl in both the BXD and the EUCIB crosses are in agreement.

\section{Mapping of Celsr 1 in the Human Genome}

Having determined the map position of the gene in the mouse, we decided to obtain mapping information for the human orthologous locus. Reduced stringency screening of a human cosmid library with ME2(2) and ME2(19) mouse CDNA clones resulted in the isolation of six overlapping cosmids that represent part of the human Cessrl locus. We determined the chromosomal location of the human Celsr 1 locus by FISH using two cosmid clones, ME2HC6 and ME2HC2O. In a sample size of 25 metaphases, signals were obtained to the long arm of one of the $\mathrm{G}$ group autosomes, either chromosome 21 or 22 (Fig. 5A). To resolve this ambiguity, the two cosmids were additionally hybridized to a trisomy 21 karyotype, and only two signals were observed (Fig. 5B); thus the human Celsr 1 locus maps to chromosome 22q13.3. These data are consistent with the conserved synteny between the region of mouse chromosome 15 containing Celsr 1 and the distal end of human chromosome 22 (Bucan et al., 1993).

\section{DISCUSSION}

The Celsr 1 gene encodes a novel developmentally regulated seven-pass transmembrane protein whose $\mathrm{N}$ -

FIG. 3. In situ hybridization of Celsr 1 transcripts in coronal sections of adult mouse brain. Dark-field photomicrographs of Celsr 1 transcripts show expression in (A) the ependymal cell layer of thelateral ventricle and the choroid plexus (arrow), (B) the ependymal cell layer of the third ventricle, and (C) the ependymal cell layer of the fourth ventricle in the area postrema (ap); (D - F ) light-field photomicrographs of the same brain areas. (G) Dark-field photomicrograph of a coronal section of the brain showing the absence of labeled cells in the ependymal cell layer of the lateral ventricle after hybridization with a sense strand probe. Scale bar, $200 \mu \mathrm{m}$. 


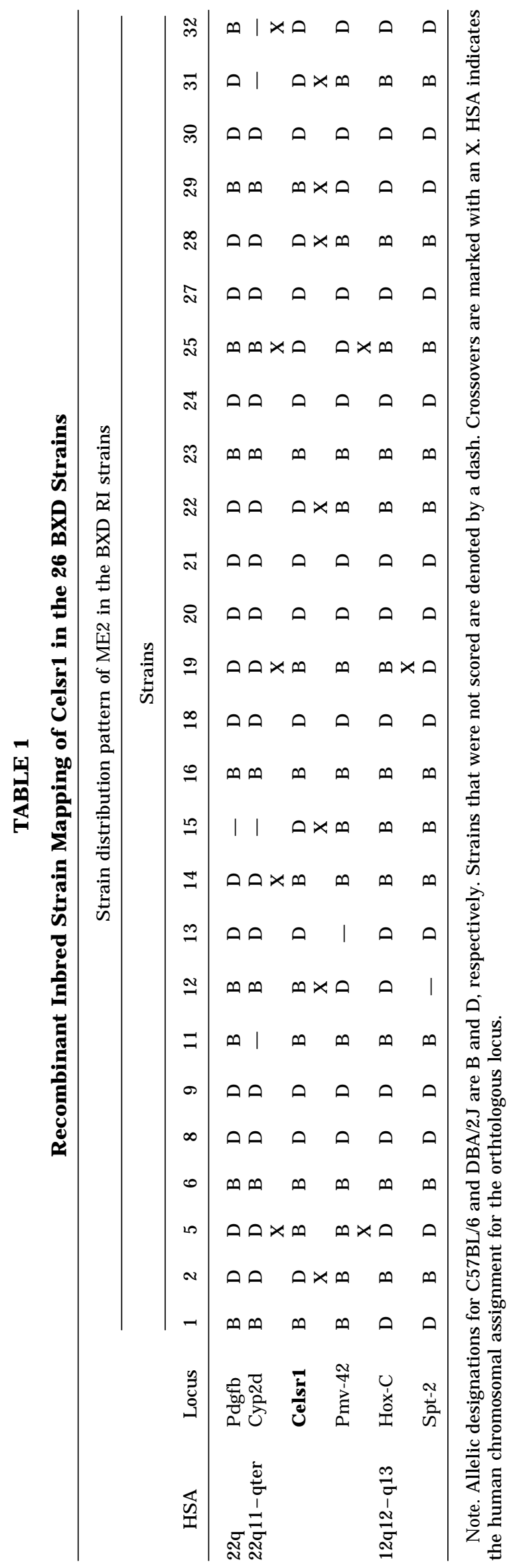

terminal extracellular domain contains motifs that are recognized as mediators of protein-protein interactions. The structure of the Celsr 1 protein, its putative G-linked signaling properties, and the spatiotemoporally restricted expression suggest that it is a receptor involved in contact-mediated communication. Its expression during mouse embryonic development is confined to ectodermal derivatives.

Our present results also show that the expression of Celsrl mRNA continues in the adult brain, where expression was seen mainly in the ependymal cell layer of the cerebroventricular system and in the choroid plexus and the area postrema. Our results do not exclude the possibility of other sites of expression in the brain at lower levels than we were able to detect by in situ hybridization. The function of the Celsr 1 receptor in the mouse brain will remain unclear until the identification of the endogenous ligand; however, the localization is consistent with a possible role in sensory processing. The presence of Celsr 1 transcripts in sites that are highly vascularized and/or in direct contact with cerebrospinal fluid (CSF) suggests that the receptor may be involved in the regulation of secretion of a number of neurohormones into CSF and may also play a role in signal transduction between blood, CSF, and neuronal tissue. The choroid plexus may constitute a paracrine system (Stylianopoulou et al., 1988), and it is possible that the Celsr 1 receptor is involved in cellcell signaling at this site in the adult brain; the ependymal layer of the ventricles and the circumventricular organs are sites that are known to contain a variety of hormones and neurotrophic factors and their receptors, including vasopressin ( urzak et al., 1993; Kato et al., 1995), insulin-likegrowth factor I/I I (Hynes et al., 1988; Marks et al., 1991; Stylianopoulou et al., 1988), N otch2 (Higuchi et al., 1995), and nerve growth factor (Timmusk et al., 1995).

The map position of Celsr 1 in the mouse suggests that it lies within the same region as three known mutations whose phenotypes are compatible with the early developmental and neural-specific expression of this gene; Blind (BId), stargazer (stg), and waggler (wag). It has been shown that wag is allelic to stg (Sweet, 1993). stg has been shown to map proximal to D15Mit69 and D15Mit70 (V. Letts and W. Frankel, pers. comm.). Both these markers give 4/19 recombinants with Celsrl in the EUCIB backcross analysis, placing them proximal to D15Mit107. Celsr1 therefore cannot be a candidate gene for stg or wag.

Bld is a semidominant mouse mutant that has been mapped to mouse chromosome 15 with respect to the coat color markers underwhite (uw), belted (bt), and Caracul (Ca). The gene order is centromere- uw- 28.2 $\pm 5.1 \mathrm{cM}-\mathrm{Bld}-14.9 \pm 2.7 \mathrm{cM}-\mathrm{bt}-11.8 \pm 3.2 \mathrm{cM}-\mathrm{Ca}$ (Teicher and Caspari, 1978). This extremely crude mapping places Bld in the same general region as Celsr 1: the precision of the mapping is insufficient to allow us to determine whether Celsrl is a candidate for Bld. Nevertheless, the expression pattern of Celsr 1 , 

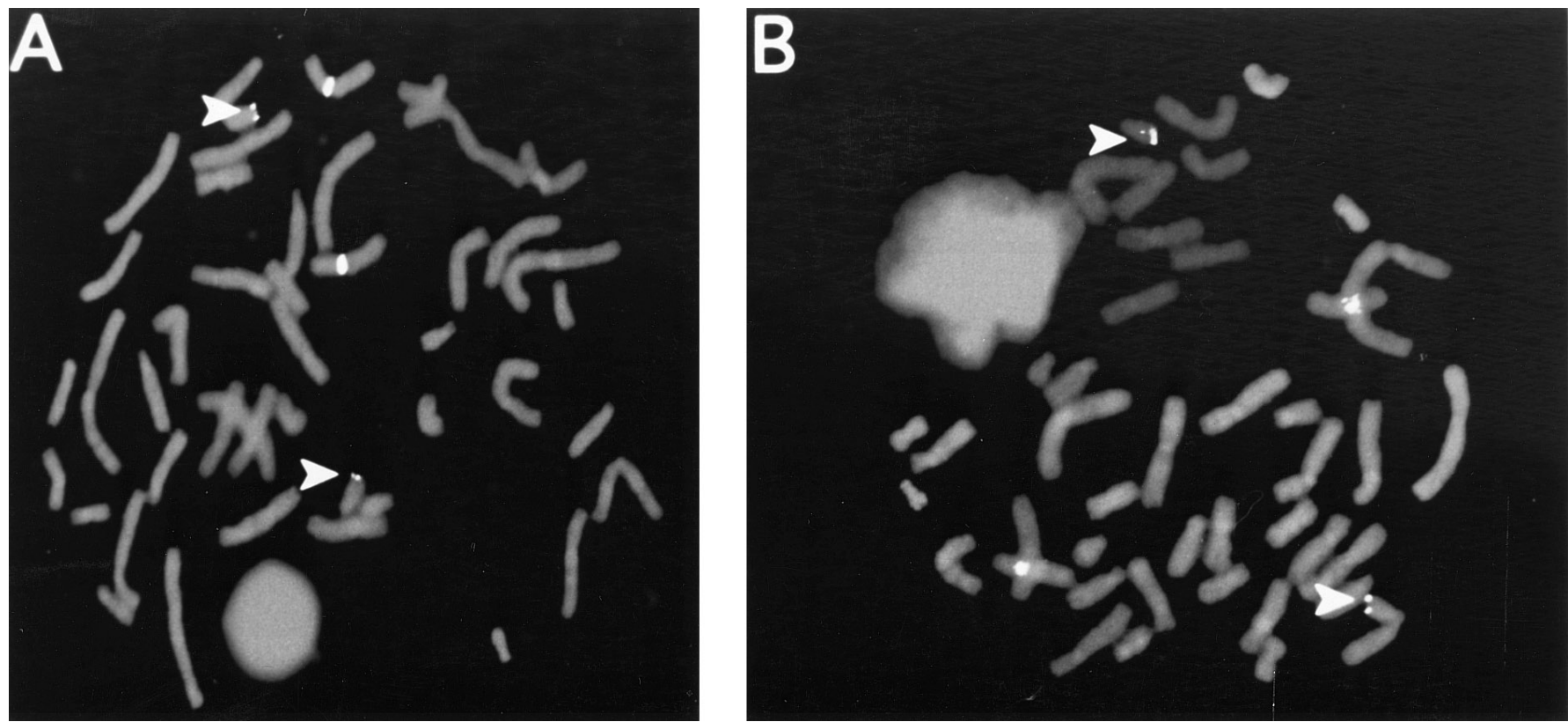

FIG. 5. Mapping of the human Celsrl locus to chromosome 22qter. FISH of cosmid ME $2 \mathrm{HC} 20$ on (A) normal karyotype and (B) trisomy 21 karyotype. Cosmid ME2HC6 gave similar results. White arrowheads indicate Celsr1-specific signals. The other marker used was a centromeric probe for chromosome 11.

when compared to the BId phenotype, makes it an attractive potential candidate. Bld homozygotes are embryonic lethals that die during early development at around 8 d.p.c., with the major phenotypic defect occurring during gastrulation. Bld heterozygotes are born blind because they fail to develop complete eyelids, and as a consequence mice are born with open eyes, leading to damage of the cornea (Watson, 1968). Celsr 1 expression in the nascent eyelid is an interesting feature of later stages of embryogenesis (Fig. 2). We have been unable to analyze the Celsrl gene in BId mice since the mutant is extinct. The possibility thus remains that Celsr 1 is a candidate for Bld.

In humans, deletions of 22q13.3 are associated with a number of phenotypic defects including developmental delay, hypotonia, and dysmorphic facial features (Nesslinger et al., 1994). This region overlaps with the map position of Celsr 1. Both Bld and the 22qter deletion syndrome phenotypes are very specific and coincident with the spatiotemporal expression of the Celsrl gene. In humans, it will be important to establish the relationship of Celsr 1 to the complex deletion syndrome by high-resolution mapping. In the mouse, a null mutant created by an ES cell-mediated germline mutation will be required to gain insight into the role of the Celsr 1 receptor in embryogenesis.

\section{ACKNO WLEDGMENTS}

We thank Anna-Maria Frischauf for the gift of a human cosmid library; Brigid Hogan for the gift of a mouse 8.5-d.p.c. cDNA library; Ben Taylor for his help with the analysis of the Celsr 1 SDP in the BXD RI series; Maria Breen and Mary Kelly at the UK Medical Research Council Resource Centre for help with the EUCIB analysis; and Verity Letts and WayneF rankel for communicating results prior to publication. This work was supported by a UK Medical Research Council HGMP directed program studentship (A.-K.H.) and The Wellcome Trust.

\section{REFERENCES}

Baud, V., Chissoe, S. L., Viegas-Pequignot, E., Diriong, S., Cong N'Guyen, V., Roe, B. A., and Lipinski, M. (1995). EMR1, an unusual member in the family of hormone receptors with seven transmembrane segments. Genomics 26: 334- 344.

Breen, M., Deakin, L., Macdonald, B., Miller, S., Sibson, R., Tarttelin, E., Avner, P., Bourgade, F., Guenet, J .-L.,, Montagutelli, X., Poirier, C., Simon, D., Tailor, D., Bishop, M., Kelly, M., Rysavy, F., Rastan, S., N orris, D., Shepherd, D., Abbott, C., Pilz, A., Hodge, S., J ackson, I., Boyd, Y., Blair, H., Maslen, G., Todd, J . A., Reed, P. W., Stoye, P., Ashworth, A., McCarthy, L., Cox, R., Schalkwyk, L., Lehrach, H., Klose, J., Gangadharan, U., and Brown, S. (1994). Towards high resolution maps of the mouse and human genomes-A facility for ordering markers to $0.1 \mathrm{cM}$ resolution. Hum. Mol. Genet. 3: 621- 627.

Bucan, M., Gatalica, B., Nolan, P., Chung, A., Leroux, A., Grossman, M. H., Nadeau, J . H., Emanuel, B. S., and Budarf, M. (1993). Comparative mapping of 9 human chromosome $22 q$ loci in the laboratory mouse. Hum. Mol. Genet. 2: 1245- 1252.

Church, G. M., and Gilbert, W. (1984). Genomic sequencing. Proc. Natl. Acad. Sci. USA 83: 7821- 7825.

Chomczynski, P., and Sacchi, N. (1987). Single-step method of RNA isolation by acid guanidinium thiocyanate- phenol - chloroform extraction. Anal. Biochem. 162: 156-159.

Conlon, R. A., and Rossant, J . (1992). Exogenous retinoic acid rapidly induces anterior ectopic expression of murine Hox-2 genes in vivo. Devel opment 116: 357- 368.

Coughlin, S. R. (1994). Expanding horizons for receptors coupled to G proteins: Diversity and disease. Curr. Opin. Cell Biol. 6: 191197.

Davis, C. G. (1990). The many faces of epidermal growth factor re peats. New Biologist 2: 410-419.

Ehrich, E., Craig, A., Poutska, A., Frischauf, A.-M., and Lehrach, 
H. (1987). A family of cosmid vectors with the multi-copy R6K replication origin. Gene 57: 229-237.

Fahrner, K., Hogan, B. L. M., and Flavell, R. A. (1987). Transcription of $\mathrm{H}-2$ and Qa genes in embryonic and adult mice. EMBO J . 6: 1265- 1271.

Geiger, B., and Ayalon, O. (1992) Cadherins. Annu. Rev. Cell Biol. 8: $307-332$.

Godfrey, P., Rahal, J . O., Beamer, W. G., Copeland, N. G., J enkins, N. A., and Mayo, K.E. (1993). GHRH receptor of little mice contains a missense mutation in the extracellular domain that disrupt receptor function. Nature Genet. 4: 227- 232.

Hamann, J ., Eichler, W., Hamann, D., Kerstens, H. M., Poddighe, P. J ., Hoovers, J. M., Hartmann, E., Strauss, M., and van Lier, R. A. (1995). Expression cloning and chromosomal mapping of the leukocyte activation antigen CD97, a new seven-span transmembrane molecule of the secretin receptor superfamily with an unusual extracellular domain. J . I mmunol. 155: 1942- 1950.

Higuchi, M., Kiyama, H., Hayakawa, T., Hamada, Y., and Tsujimoto, Y. (1995). Differential expression of Notch1 and Notch2 in developing and adult mouse brain. Mol. Brain Res. 29: 263- 272.

Hogan, B., Constantini, F., and Lacey, E. (1986). "Manipulating the Mouse Embryo-A Laboratory Manual," Cold Spring Harbor Press, Cold Spring Harbor, NY.

Hoovers, J. M. N., Mannens, M., J ohn, R., Bliek, J ., van Heyningen, V., Porteus, D. J ., Leschot, N. J ., Westerveld, A., and Little, P. F. R. (1992). High-resolution localization of 69 potential zinc finger protein genes: A number are clustered. Genomics 12: 254- 263.

Hosoda, K., Hammer, R.E., Richardson, J.A., Baynash, A. G., Cheung, J . C., Giaid, A., and Yanagisawa, M. (1994). Targeted and natural (piebald-lethal) mutations of endothelin-B receptor gene produce magacolon associated with spotted coat colour in mice. Cell 79: 1267-1276.

Hynes, M. A., Brooks., P. J ., Van Wyk, J .J ., and Lund, P. K. (1988). Insulin-like growth factor II messenger ribonucleic acids are synthesized in the choroid plexus of the rat brain. Mol. Endocrinol. 2: 47-54.

J urzak, M., Fahrenholz, F., and Gerstberger, R. (1993). Vasopressin anti-idiotypic antibody staining in the rat brain: Colocalization with $\left.{ }^{35} \mathrm{~S}\right]\left[\mathrm{pGlu}^{4}, \mathrm{Cyt}^{6}\right] \mathrm{AVP}{ }_{(4-9)}$ binding sites. J . Neuroendocrinol . 5: 523-531.

Kato, Y., I garashi, N., Hirasawa, A., Tsujimoto,G., and Kobayashi, M. (1995). Distribution and deveopmental changes in vasopressin V2 receptor mRNA in rat brain. Differentiation 59: 163- 169.

Kolakowski, L. F., J r. (1994). GCRDb-A G protein-coupled receptor database. Receptors Channels 2: 1-7.

Koopman, P. (1993). Analysis of gene expression by reverse transcriptase-polymerase chain reaction. In "Essential Developmental Biology: A Practical Approach" (C. D. Stern and P. W. H. Holland, Eds.), pp. 233-242, IRL Press, Oxford.

Little, P. F. R. (1987). Choice and use of cosmid vectors. In "Gene Cloning: A Practical Approach". (D. M. Glover, Ed.), Vol. 3, pp. 19-42, IRL Press, Oxford.

Lin, C., Lin, S. C., Chang, C. P., and Rosenfeld, M. G. (1993). Pit-1 dependent expression of the receptor for growth hormone releasing factor mediates pituitary cell growth. Nature 360: 711- 712.

Manly, K. F., and Elliot, R. W. (1991). RI manager, a microcomputer program for analysis of data from recombinant inbred strains. Mamm. Genome 1: 123-126.

Marks, Porte, D., and Baskin, D. G. (1991). Localization of type I insulin-like growth factor messenger RNA in the adult rat brain by in situ hybridization. Mol. Endocrinol. 5: 1158- 1168.

Nesslinger, N.J ., Gorski, J . L., Kurczynski, T. W., Shapira, S. K., Siegel-Bartelt, J ., Dumanski, J . P., Cullen, R. F., J r., French, B. N., and McDermid, H. E. (1994). Clinical, cytogenetic and molecular characterisation of seven patients with deletions of chromosome 22q13.3. Am. J . Hum. Genet. 54: 464-472.

Patthy, L. (1992). A family of laminin-related proteins controlling ectodermal differentiation in Drosophila. FEBS Lett. 298: 182184.

Puffenberger, E. G., Hosoda, K., Washington, S. S., Nakao, K., de Wit, D., Yanagisawa, M., and Chakravarti, A. (1994). A missense mutation of the endothelin-B receptor gene in multigenic Hirschprung's disease. Cell 79: 1257-1260.

Robbins, L. S., Nadeau, J . H., J ohnson, K. R., Kelly, M. A., RoselliRehfus, L., Baack, E., Mountjoy, K. G., and Cone, R. D. (1993). Pigmentation phenotypes of variant extension locus alleles result from point mutations that alter MSH receptor function. Cell 72: 827-834.

Ronne, M. (1985). Double synchronization of human Iymphocyte cultures: Selection for high-resolution banded mataphases in the first and second division. Cytogenet. Cell Genet. 39: 292-295.

Sambrook, J ., Fritsch, E. F., and Maniatis, T. (1989). "Molecular Cloning: A Laboratory Manual," 2nd ed., Cold Spring Harbor Press, Cold Spring Harbor, NY.

Sheward, W. J ., Lutz, E. M., and Harmar, A. J . (1995). The distribu-

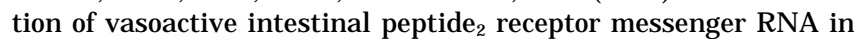
the rat brain and pituitary gland as assessed by in situ hybridization. Neuroscience 67: 409-418.

Stylianopoulou, F., Herbert, J., Soares, M. B., and Efstratiadis, A. (1988). Expression of the insulin-like growth factor II gene in the choroid plexus and the leptomeninges of the adult rat central nervous system. Proc. Natl. Acad. Sci. USA 85: 141- 145.

Sweet, H. (1993). Waggler and stargazer are allelic. Mouse Genome 91: $312-313$.

Taylor, B. A. (1989). Recombinant inbred strains. In "Genetic Variants and Strains of the Laboratory Mouse" (M. F. Lyon and A. G. Searle, Eds.), pp. 773-796, Oxford Univ. Press, Oxford.

Teicher, L.S., and Caspari, E.W. (1978). The genetics of blind-a lethal factor in mice. J . Hered. 69: 86-90.

Timmusk, T., Mudo, G., Metsis, M., and Belluardo, N. (1995). Expression of mRNAs for neurotrophins and their receptors in the rat choroid plexus and dura mater. NeuroReport 6: 1997- 2000.

Watson, M. L. (1968). Blind-a dominant mutation in mice. J . Hered. 59: $60-64$

Wilkinson, D. G. (1992). Whole mount in situ hybridisation of vertebrate embryos. In "In Situ Hybridisation: A Practical Approach" (D. G. Wilkinson Ed.), pp 75-84, IRL Press, Oxford. 